\title{
Clinical outcome and prognostic factors in elderly traumatic brain injury patients receiving neurointensive care
}

\author{
Samuel Lenell ${ }^{1}$ (D) $\cdot$ Lena Nyholm $^{1} \cdot$ Anders Lewén $^{1} \cdot$ Per Enblad $^{1}$ \\ Received: 7 January 2019 / Accepted: 25 March 2019 / Published online: 13 April 2019 \\ (C) The Author(s) 2019
}

\begin{abstract}
Background The probability of favorable outcome after traumatic brain injury (TBI) decreases with age. Elderly, $\geq 60$ years, are an increasing part of our population. Recent studies have shown an increase of favorable outcome in elderly over time. However, the optimal patient selection and neurointensive care (NIC) treatments may differ in the elderly and the young. The aims of this study were to examine outcome in a larger group of elderly TBI patients receiving NIC and to identify demographic and treatment related prognostic factors.

Methods Patients with TBI $\geq 60$ years receiving NIC at our department between 2008 and 2014 were included. Demographics, co-morbidity, admission characteristics, and type of treatments were collected. Clinical outcome at around 6 months was assessed. Potential prognostic factors were included in univariate and multivariate regression analysis with favorable outcome as dependent variable.

Results Two hundred twenty patients with mean age 70 years (median 69; range 60-87) were studied. Overall, favorable outcome was 46\% (Extended Glasgow Outcome Scale (GOSE) 5-8), unfavorable outcome 27\% (GOSE 2-4), and mortality $27 \%$ (GOSE 1). Significant independent negative prognostic variables were high age $(p<0.05)$, multiple injuries $(p<0.05)$, GCS $\mathrm{M} \leq 3$ on admission $(p<0.05)$, and mechanical ventilation $(p<0.001)$.

Conclusions Overall, the elderly TBI patients $\geq 60$ years receiving modern NIC in this study had a fair chance of favorable outcome without large risks for severe deficits and vegetative state, also in patients over 75 years of age. High age, multiple injuries, GCS $\mathrm{M} \leq 3$ on admission, and mechanical ventilation proved to be independent negative prognostic factors. The results underline that a selected group of elderly with TBI should have access to NIC.
\end{abstract}

Keywords Traumatic brain injury $\cdot$ Elderly $\cdot$ Outcome $\cdot$ Quality register $\cdot$ Neurointensive care $\cdot$ Prognostic factors

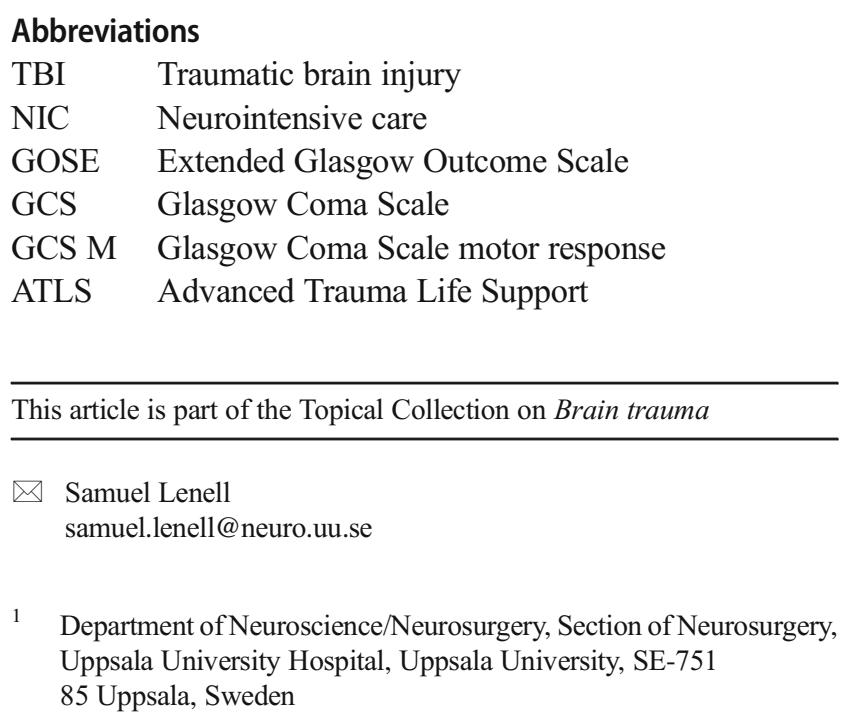

\section{Abbreviations}

NIC Neurointensive care

GOSE Extended Glasgow Outcome Scale

Glasgow Coma Scale

GCS M Glasgow Coma Scale motor response
CVD Cardiovascular disease

ICP Intracranial pressure

CT Computed tomography

EVD External ventricular drain

CPP Cerebral perfusion pressure

SBP Systolic blood pressure

CVP Central venous pressure

CSF Cerebrospinal fluid

ASDH Acute subdural hematoma

EML Evacuated mass lesions

INR International normalized ratio

ICH Intracerebral hematoma

OR Odds ratio

$\mathrm{EDH} \quad$ Epidural hematoma

NOAC Non-vitamin K antagonist oral anticoagulants

LMWH Low molecular weight heparin 


\section{Introduction}

Outcome after traumatic brain injury (TBI) has improved over time with the development of neurointensive care (NIC) $[3,4$, $9,10,26,27,30,48]$ despite the fact that favorable outcome decreases with increasing age [16, 21, 28, 29, 38, 44], and there is an increasing proportion of elderly in the TBI population $[17,19,33,34]$. The United Nations reports that the population aged 60 or older is growing faster than all the younger age groups and expects the number of persons over 60 years to be more than doubled by 2050 [46]. Elderly are prone to trauma from falls. One third of every person above 60 years and every other person above 80 years have a falling accident every year [23]. The management of elderly patients with traumatic head injury constitutes a tremendous challenge in the future. An updated periodic evaluation of NIC of TBI patients made by us showed substantial increase of the proportion of patients $>60$ years treated from 16 to $30 \%$ between 1996-1997 and 2008-2009 [22]. Furthermore, when clinical outcome was evaluated in the elderly TBI patients who received NIC, $51 \%$ of patients age $\geq 65$ had favorable outcome [28]. Those relatively favorable results indicate that elderly patients with TBI should not be excluded from NIC. However, the optimal patient selection and most beneficial treatments may differ in the elderly and the young. Elderly patients have comorbidities to a higher degree, are more likely to use anticoagulants, and respond less well to rehabilitation [5]. Therefore, it is important to gain more knowledge about elderly TBI patients. The aims of this study were to examine outcome in a larger group of elderly TBI patients receiving NIC and to identify demographic- and treatment-related prognostic factors specifically in the elderly.

\section{Material and methods}

\section{Referral of patients}

The Department of Neurosurgery at the Uppsala University Hospital in Sweden provides highly specialized NIC for a population of approximately 2 million people living in the central part of Sweden. Patients arriving at local hospitals are stabilized according to the ATLS principles and then referred to Uppsala for tertiary care (the most distant local hospital $382 \mathrm{~km}$ away) [11].

\section{Patient selection and data collection}

Information about clinical characteristics, management, and clinical outcome are recorded for all TBI patients treated at the NIC unit in Uppsala in the Uppsala Traumatic Brain Injury register [31].TBI patients $\geq 60$ years of age registered between 2008 and 2014 were eligible for the study. In total, 249 patients were identified. After exclusion of 29 elderly patients, 220 remained to be the studied. The patients were excluded for the following reason: patients admitted to the NIC unit $\geq$ 5 days after the trauma $(n=10)$, or treated successfully at the NIC unit within $24 \mathrm{~h}(n=6)$; patients with both pupils wide and non-reacting on arrival at the NIC unit $(n=4)$ (i.e., patients with an obvious predestined fatal clinical course $[1,7]$ ); patients with gunshot wound to the head $(n=1)$; patients lost to follow-up $(n=8)$.

\section{Data studied}

The following parameters were studied: primary or secondary transfer, sex, age, cause of trauma, multiple injuries, trauma under influence of drugs/alcohol, acute surgery before arrival, GCS on admission, medical history (brain injury/disease, previous traumatic brain injury, diabetes mellitus, hypertension/ cardiovascular disease (CVD), antithrombotic drugs (subgrouped by antiplatelet, warfarin, non-vitamin $\mathrm{K}$ antagonist oral anticoagulants (NOAC), and low molecular weight heparin (LMWH)), and ethylism), craniotomy, cause of craniotomy, decompressive hemicraniectomy, intracranial pressure (ICP) monitoring, mechanical ventilation, and NIC mortality.

\section{Radiology}

The computed tomography (CT) scans from the admission were classified retrospectively according to Marshall Classification [25] by one of the authors (S.L.).

\section{Neurointensive care}

All patients were treated according to the standardized escalated management protocol, described in detail earlier [10], and summarized below:

Basal treatment All unconscious patients (Glasgow Coma Scale motor response $(\mathrm{GCS} \mathrm{M}) \leq 5)$ are intubated and mechanically ventilated. Intubated patients are moderately hyperventilated $\left(\mathrm{PaCO}_{2} 4.0-4.5 \mathrm{kPa}\right)$ on admission with the aim of normoventilation as soon as possible when ICP allows. Propofol (Propofol-LipuroB; Braun Medical, Danderyd, Sweden) is used for sedation and morphine for analgesia. ICP is monitored in unconscious patients using an external ventricular drain (EVD) or an intraparenchymal pressure probe. When EVD is used, ICP is measured with the pressure dome at the level of the lateral ventricles. Arterial blood pressure is measured with the pressure dome at heart level. Patients are positioned in bed with $30^{\circ}$ head elevation to facilitate venous outflow. Clinical neurological status is monitored using frequent wake-up tests. Lesions causing significant mass effect, extracerebral hematomas or contusions, are surgically evacuated except when coagulopathy is resistant to 
therapy. Prophylactic anticonvulsants are not used. Thromboprophylaxis are used when the risk for new intracranial bleedings are deemed low and continued until patients have been mobilized. Treatment goals are as follows: ICP $<$ $20 \mathrm{mmHg}$, cerebral perfusion pressure (CPP) $>60 \mathrm{mmHg}$, systolic blood pressure (SBP) $>100 \mathrm{mmHg}$, central venous pressure (CVP) 0-5 cm $\mathrm{H}_{2} 0, \mathrm{pO}_{2}>12 \mathrm{kPa}$, blood glucose 5$10 \mathrm{mmol} / \mathrm{L}$, electrolytes within normal range, normovolemia, and body temperature $<38^{\circ} \mathrm{C}$. If ICP is increased $>20 \mathrm{mmHg}$ without mass lesions, intermittent cerebrospinal fluid (CSF) drainage of small volumes $(1-2 \mathrm{ml})$ are used during the early period when there are risks of expanding hematomas and brain swelling. Later, CSF is drained using an open system against a pressure level of $15-20 \mathrm{mmHg}$ if needed.

Step 1A In case of persisting ICP problems, the treatment is escalated to Step 1A with no wake-up test. This entails continuous sedation with propofol and stress reduction with $\beta 1$ antagonist metoprolol (Seloken ${ }^{\circledR}$, AstraZeneca AB Södertälje, Sweden) (0.2-0.3 mg/kg/24 h as an infusion) and $\alpha 2$-agonist clonidin (Catapresan ${ }^{\circledR}$, BoehingerIngelheim $\mathrm{AB}$ Stockholm Sweden) $(0.5-1.0 \mu \mathrm{g} / \mathrm{kg} \times 8$ or the same dose as an infusion).

Step 1B When the ICP problems continue, barbiturate coma treatment with infusion of thiopental (Pentocur, Abcur AB, Helsingborg, Sweden) is initiated provided that there is no shift of the midline. Bolus dose of $4-8 \mathrm{mg} / \mathrm{kg}$ is given as repeated $50 \mathrm{mg}$ injections until ICP is $<20 \mathrm{mmHg}$ followed by an infusion of $5-10 \mathrm{mg} / \mathrm{kg} / \mathrm{h}$ for $6 \mathrm{~h}$ and thereafter $2-$ $5 \mathrm{mg} / \mathrm{kg} / \mathrm{h}$ as required to control ICP. The lowest possible dose is used to keep ICP $<20 \mathrm{mmHg}$ and burst-suppression on electroencephalogram (EEG) is not the goal. During this treatment, a CPP as low as $50 \mathrm{mmHg}$ is allowed. Thiopental concentration $>380 \mu \mathrm{mol} / \mathrm{L}$ is avoided. Because of the high risk of severe side effects with barbiturate coma treatment in elderly, this therapy was only exceptionally escalated to this step in old patients.

Step 2 Decompressive craniectomy [42] is used when Step 1B is insufficient to reduce ICP or when adverse effects of the thiopental treatment are observed. Bi-fronto-temporal craniectomies are done, sparing the bone ridge in the midline when there are no mass lesions. When there is a shift of the midline and no localized mass lesions to evacuate, a hemicraniectomy is done.

\section{Evaluation of outcome}

Clinical outcome was assessed after around 6 months using structured telephone interviews for the Extended Glasgow Outcome Scale (GOSE) [39, 43]. The interview was done by a few selected persons.
The outcome was categorized in favorable (GOSE 5-8), unfavorable (GOSE 2-4), and dead (GOSE 1).

\section{Statistical methods}

To compare different age groups, Pearson's Chi-squared test was used. Patients and treatment factors were analyzed using univariate logistic regression. Multivariate logistic regression analysis was performed with favorable outcome (GOSE 5-8) as dependent variable. Admission variables were included as explanatory variables, and admission together with treatment variables was also analyzed. All explanatory variables were dichotomized except age. IBM SPSS Statistics for Windows was used.

\section{Results}

\section{Age distribution}

The mean age of the 220 patients was 70 years (median 69; range $60-87$ ). The age distribution showed that most of the patients were between 60 and 75 years (Fig. 1).

\section{Patient characteristics on admission}

The patient characteristics are presented in Table 1 for all patients $>60$ years old, for patients $60-74$ years old, and for patients $75-89$ years old. There were 170 patients $60-74$ years old and 50 patients $75-89$ years old. There was no significant difference in sex between the two age groups. The most common cause of trauma was falls which occurred in $77 \%$ of all cases (170 patients). There was no significant difference between the two age groups. In both age groups, around $90 \%$ of the patients were admitted in GCS $M \geq 4$. Multiple injuries were found in $25 \%$ of the $60-74$-year-old patients and in $10 \%$ of the $75-89$ years old $(p<0.05)$. Trauma under the influence of alcohol was almost 5 times as common in the 60-74-year-old patients compared to the older patients, $26 \%$ vs $6 \%$, respectively, $(p<0.01)$.

Overall, the most common type of injury dominating TBI was acute subdural hematoma (ASDH; 43\%) followed by contusions (29\%). In the 60-74-year-old group, contusions were the dominating injury type, and occurred in $35 \%$ of the patients, compared to $10 \%$ in the 75-89-year-old group $(p<0.001)$. In the 75-89-year-old group, the dominating injury type was ASDH, occurring in $76 \%$ of the patients compared to $34 \%$ in the $60-74$ years old $(p<0.01)$ (Table 1).

When the initial CT scans were classified according to Marshall Classification (Table 1), diffuse injury II was the most common class with $41 \%$ in patients $60-74$ years old and $22 \%$ in patients $75-89$ years old $(p<0.05)$. Evacuated mass lesion was the most common Marshall Classification in patients 75 89 years old and occurred in $40 \%$ of those patients. 
Fig. 1 Age distribution

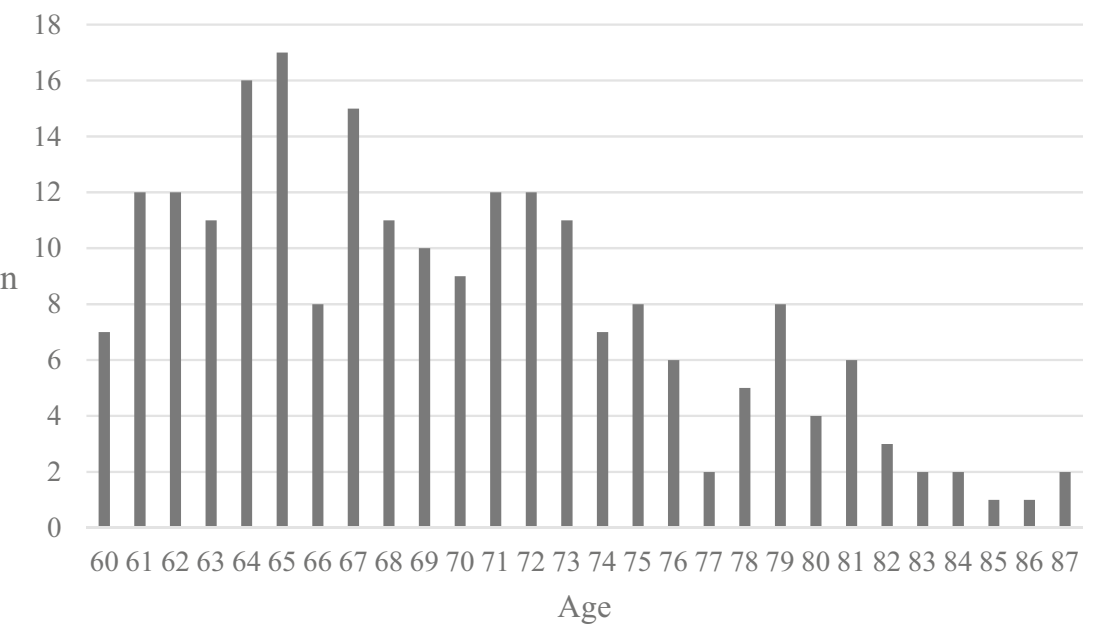

Regarding the medical history (Table 1), 54\% of all elderly had hypertension/CVD and 37\% used antithrombotic drugs. One fifth of all 220 patients $(20 \%)$ had a history of previous brain injury/disease before the trauma, but only $4 \%$ of those were a previous TBI. Among patients 60-74 years old, $48 \%$ had hypertension/CVD in the medical history compared to $72 \%$ in patients $75-89$ years old $(p<0.01)$. Antithrombotic drugs were almost twice as common in 75-89-year-old patients compared to 60-74-year-old patients, $62 \%$ and $30 \%$, respectively $(p<0.001)$. Looking at the specific antithrombotic drugs, warfarin was four times as common in 75-89-yearold patients compared to patients $60-74$ years old; $42 \%$ vs $8 \%$. Among patients $60-74$ years old, $30 \%$ of had a history of ethylism compared to $10 \%$ among patients $75-89$ years old $(p<0.01)$.

\section{Management characteristics}

Among all 220 elderly patients, 177 (80\%) received mechanical ventilation for a mean of 7 days (median 6, range 1-21), and $118(53 \%)$ had ICP monitoring for a mean of 10 days (median 8, range 2-25) (Table 2). Eighteen patients $(8 \%)$ had been operated with evacuation of ASDH at the referring hospital due to acute herniation before arrival (Table 2). Ninety-five patients (43\%) had a craniotomy done during NIC, most commonly due to ASDH which occurred in 80 patients $(36 \%)$ followed by evacuation of contusions in 25 patients (11\%). Decompressive hemicraniectomy was done in 9 patients (4\%). Thirty patients $75-89$ years old $(60 \%)$ had a craniotomy compared to 65 patients $60-74$ years old $(38 \%)(p \leq 0.01)$. Three patients received thiopental.

\section{Clinical outcome}

Follow-up of surviving patients was made after 7.8 months in mean (median 7, range 5-28). When outcome was graded with the Extended Glasgow Outcome Scale, 43 patients
(20\%) were GOSE 8 (upper good recovery), 40 (18\%) were GOSE 7 (lower good recovery), 10 (5\%) were GOSE 6 (upper moderate disability), 8 (4\%) were GOSE 5 (lower moderate disability), 21 (10\%) were GOSE 4 (upper severe disability), 37 (17\%) were GOSE 3 (lower severe disability), 2 patients (1\%) were in GOSE 2 (vegetative state), and 59 patients (27\%) were GOSE 1 (dead; 17 (8\%) died at the NICU) (Fig. 2). The clinical outcome by age groups is summarized in Fig. 3. Patients 60-69 years old showed favorable outcome in around $50 \%$ of the cases and $<20 \%$ died. Patients 70 74 years old almost also showed favorable outcome in $50 \%$ of the cases and around $35 \%$ died. In patients 75-84 years of age, favorable outcome was around $30 \%$ and declined to $25 \%$ in patients $85-89$ years old. Of the 60-74 years old, 11 patients $(6 \%)$ died at the NICU compared with $6(12 \%)$ in the 75-89 years old.

\section{Prediction of prognosis}

Univariate logistic regression analysis with favorable outcome (GOSE 5-8) as dependent variable (Table 3) showed the following significant patient variables (predictors): age $(p<0.05)$, GCS M $\leq 3$ on admission $(p<0.01)$, diffuse injury Marshall score I-IV $(p<0.001)$, and Marshall score evacuated mass lesion (EML) $(p<0.001)$ and warfarin $(p<0.05)$. The following patient variables showed marginal significance (Table 3): extracerebral hematoma $(p=0.08)$, history of brain injury/disease $(p=0.056)$, and history of ethylism $(p=0.066)$ and antiplatelet $(p=0.053)$.

For the treatment variables, the significant variables were (Table 3): craniotomy $(p<0.01)$, evacuation of extracerebral hematoma $(p<0.05)$, and mechanical ventilation $(p<0.001)$.

Multivariate logistic regression analysis of admission variables showed that the significant independent variables were age $(p<0.05)$ and multiple injuries $(p<0.05)$. GCS $\mathrm{M} \leq 3$ on admission $(p=0.052)$ and EML $(p=0.078)$ showed marginal significance (Table 4). 
Table 1 Characteristics on admission

Patient and trauma characteristics

$\begin{array}{lllll}\text { All } & \frac{60-74}{n} & \% & \frac{75-89}{n} & p 60-74 \text { vs 75-89 }\end{array}$

220

\begin{tabular}{l}
\hline Total \\
Referrals \\
Sex (female) \\
Male
\end{tabular}

Multiple injuries

Under the influence of drugs/alcohol at trauma

220

167

61

159

47

47

Cause of trauma

Bicycle accident

Fall accident

Vehicle accident

Pedestrian hit by vehicle

Assault

Sports injury

Other

GCS motor response

6 Obeys commands

5 Localizes pain

4 Withdraws (normal flexion)

3 Stereotyped flexion

2 Stereotyped extension

1 None

GCS $\mathrm{M} \geq 4$ on admission

GCS $\mathrm{M} \leq 3$ on admission

Dominating injury type on CT

ASDH

Other

DAI

$\mathrm{EDH}$

Impression fracture ${ }^{\mathrm{a}}$

Contusions

Mixed

Normal CT

Traumatic SAH

Initial CT Marshall Classification

Diffuse injury I

Diffuse injury II

Diffuse injury III

Diffuse injury IV

Evacuated mass lesion

Non-evacuated mass lesion

Diffuse injury I-IV

Focal mass lesion

Medical history of

Brain injury/disease

Traumatic brain injury

Diabetes mellitus

Hypertension/CVD

Ethylism

Antithrombotic drugs

170

20

9

3

1

10

10

68

68
24

24

11

6

5

198

22

95

3

3
2

4

3

6

$170 \quad 50$

$\begin{array}{lll}140 & 82 & 50\end{array}$

$\begin{array}{lll}140 & 82 & 27 \\ 44 & 26 & 17\end{array}$

126

26
74

17

54

0.000

0.260

$126-74-33$

34

66

0.260

0.026

0.003

5

10

(1)

$\begin{array}{llllll}6 & 6 & 4 & 1 & 2\end{array}$

$\begin{array}{lllll}77 & 132 & 78 & 38 & 76\end{array}$

0.807

(1)

31

5

16

9

$\begin{array}{ll}38 & 8\end{array}$

6

4
2

2

0

4

36

$0 \quad 0$

$\begin{array}{ll}1 & 2 \\ 3 & 6\end{array}$

$06 \quad 48$

7

\begin{tabular}{|c|c|c|c|c|}
\hline 47 & 26 & 52 & 0.539 & \\
\hline 32 & 13 & 26 & 0.393 & \\
\hline 1 & 7 & 14 & 0.425 & \\
\hline 6 & 2 & 4 & & \\
\hline 2 & 2 & 4 & & \\
\hline 3 & 0 & 0 & & \\
\hline 89 & 46 & 92 & 0.592 & \\
\hline 11 & 4 & 8 & 0.592 & \\
\hline 34 & 38 & 76 & 0.000 & $* * *$ \\
\hline 1 & 1 & 2 & & \\
\hline 1 & 0 & 0 & & \\
\hline 2 & 0 & 0 & & \\
\hline 2 & 0 & 0 & & \\
\hline 35 & 5 & 10 & 0.001 & $* * *$ \\
\hline 14 & 3 & 6 & 0.147 & \\
\hline 0 & 0 & 0 & & \\
\hline 12 & 3 & 6 & 0.242 & \\
\hline 1 & 0 & 0 & & \\
\hline 41 & 11 & 22 & 0.016 & $*$ \\
\hline 11 & 2 & 4 & & \\
\hline 5 & 5 & 1 & & \\
\hline 28 & 20 & 40 & 0.114 & \\
\hline 14 & 12 & 24 & 0.075 & \\
\hline 58 & 18 & 36 & 0.006 & $* *$ \\
\hline 41 & 32 & 64 & 0.006 & $* *$ \\
\hline 19 & 12 & 24 & 0.480 & \\
\hline 4 & 1 & 2 & & \\
\hline 15 & 11 & 22 & & \\
\hline 48 & 36 & 72 & 0.003 & $* *$ \\
\hline 30 & 5 & 10 & 0.004 & $* *$ \\
\hline 30 & 31 & 62 & 0.000 & $* * *$ \\
\hline
\end{tabular}


Table 1 (continued)

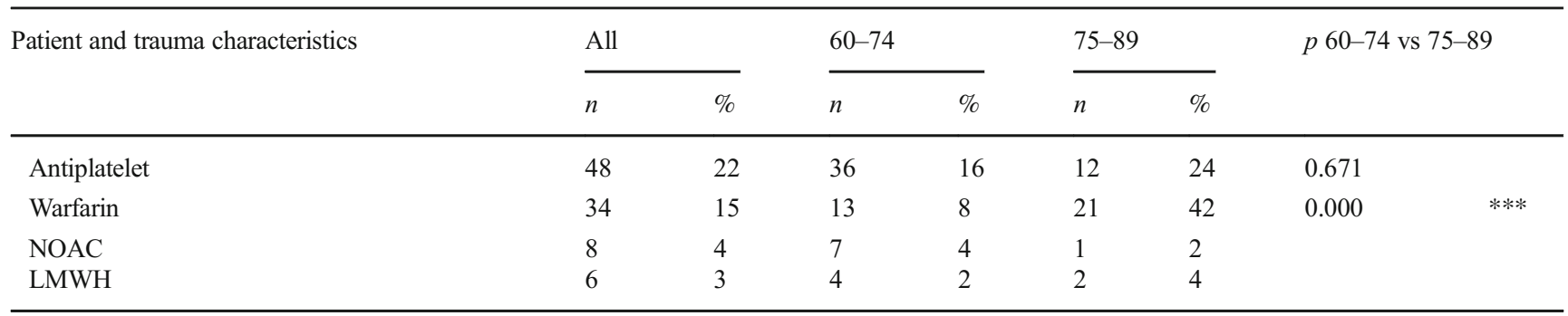

${ }^{a}$ All impression fractures also hade intracerebral or subarachnoidal blood

$* p<0.05$

$* * p<0.01$

$* * * p<0.001$

When admission variables and treatment variables were included in the multivariate logistic regression analysis, the significant independent variables were age $(p<0.05)$, GCS $\mathrm{M} \leq 3$ on admission $(p<0.05)$, multiple injuries $(p<0.05)$, and mechanical ventilation $(p<0.01)$. Variables that showed marginal significance were EML $(p=0.067)$, ethylism $(p=$ $0.073)$, warfarin $(p=0.088)$, surgery before arrival $(p=$ $0.053)$, and evacuated contusions $(p=0.055)$ (Table 5). Age was studied as a continuous variable so for every year in age there was a 0.94 odds ratio for favorable outcome, meaning the chance of favorable outcome decreased $6 \%$ with each increase of 1 year in age.

\section{Discussion}

Forty-six percent of the elderly over 60 years of age had favorable outcome (GOSE 5-8), while $27 \%$ had unfavorable outcome (GOSE 2-4), and 27\% died (GOSE 1) (Fig. 3), which indicates that NIC may be beneficial for the elderly. The rate of favorable outcome was virtually unchanged up to 75 years of age and then a slight decrease was seen with more advanced age. Unfavorable outcome did not increase after 75 years of age; it appears as the reason for the slight decrease in the proportion of favorable outcome above 75 years of age was higher mortality rather than an increased
Table 2 Management characteristics

\begin{tabular}{|c|c|c|c|c|c|c|c|c|}
\hline \multirow[t]{2}{*}{ Management } & \multicolumn{2}{|l|}{ All } & \multicolumn{2}{|c|}{$60-74$} & \multicolumn{2}{|c|}{$75-89$} & \multicolumn{2}{|c|}{$p 60-74$ vs $75-89$} \\
\hline & $n$ & $\%$ & $n$ & $\%$ & $n$ & $\%$ & & \\
\hline Total & 220 & & 170 & & 50 & & & \\
\hline Emergency craniotomy before arrival & 18 & 8 & 13 & 8 & 5 & 10 & & \\
\hline Craniotomy & 95 & 43 & 65 & 38 & 30 & 60 & 0.006 & $* *$ \\
\hline Evacuation extracerebral hematoma $^{\mathrm{b}}$ & 87 & 40 & 58 & 34 & 29 & 58 & 0.002 & $* *$ \\
\hline Evacuation EDH & 3 & 1 & 3 & 2 & 0 & 0 & & \\
\hline Evacuation ASDH & 80 & 36 & 52 & 31 & 28 & 56 & 0.001 & $* *$ \\
\hline Evacuation for both $(\mathrm{EDH}+\mathrm{SDH})$ & 4 & 2 & 3 & 2 & 1 & 2 & & \\
\hline Evacuation contusions ${ }^{\mathrm{b}}$ & 25 & 11 & 21 & 12 & 4 & 8 & 0.394 & \\
\hline Decompressive hemicraniectomy & 9 & 4 & 7 & 4 & 2 & 4 & & \\
\hline Multiple surgeries & 22 & 10 & 14 & 8 & 8 & 16 & 0.108 & \\
\hline ICP monitoring & 118 & 53 & 96 & 56 & 22 & 44 & 0.120 & \\
\hline EVD only & 21 & 10 & 19 & 11 & 2 & 4 & & \\
\hline Intraparenchymal probe only & 76 & 35 & 56 & 33 & 20 & 40 & 0.356 & \\
\hline EVD and intraparenchymal probe & 21 & 10 & 21 & 12 & 0 & 0 & & \\
\hline Days with ICP monitoring (mean) & 9.5 & & 10 & & 7.4 & & & \\
\hline Mechanical ventilation & 177 & 80 & 135 & 79 & 42 & 84 & 0.472 & \\
\hline Days with mechanical ventilation (mean) & 7.4 & & 7.6 & & 6.8 & & & \\
\hline
\end{tabular}

${ }^{\mathrm{b}}$ Some patients evacuated both extracerebral hematoma and contusions

$* p<0.05$

$* * p<0.01$

$* * * p<0.001$ 
Fig. 2 GOSE score on 6-month follow-up

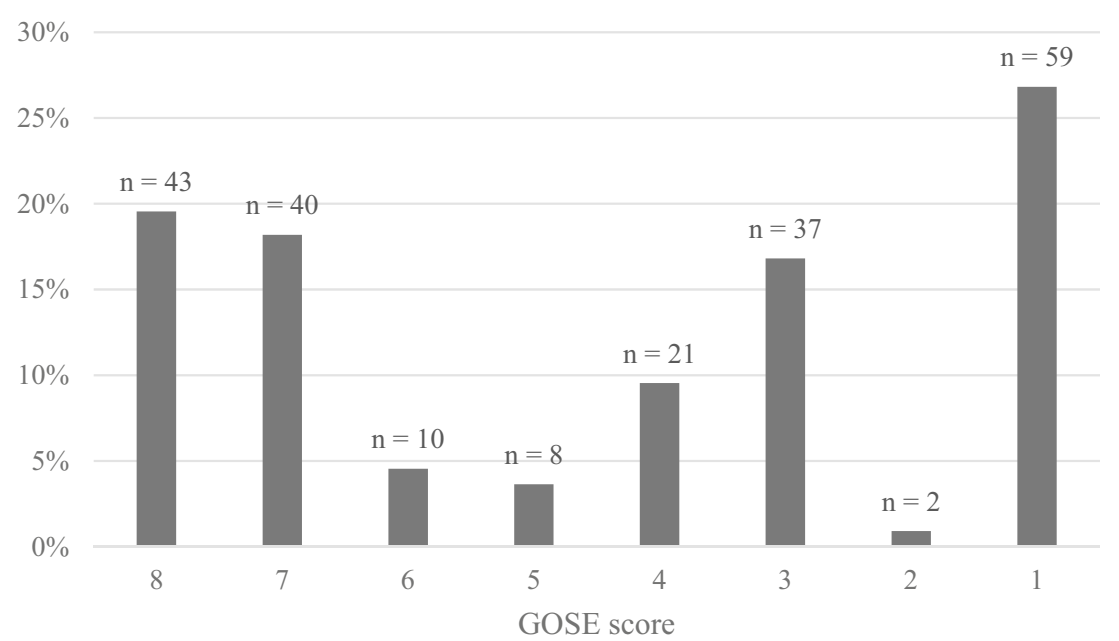

proportion of unfavorable outcome (Fig. 3). Those results are important to consider when to decide to offer NIC or not in an elderly TBI patient, taking also into consideration the general assumption that elderly are not afraid to die but to become dependent [41]. It should be emphasized, however, that these results cannot be extrapolated to the elderly population in general, since there was a selection of elderly patients judged to have a reasonable chance to achieve favorable outcome depending on, e.g., previous functional status, type of injury, level of consciousness, and co-morbidity. It is important to look at the characteristics of the elderly patients studied and try to identify prognostic factor in order to facilitate the selection of elderly TBI patients for NIC in the future.

The main cause of trauma in all elderly age groups was fall (Table 1), which is in accordance with our earlier findings [22, $28]$ as well as with the results of many other studies $[8,15,17$, $19,23,34,36,40]$. Although there was a predominant injury mechanism, there was a notable significant difference between the age groups regarding several other characteristics (Table 1). The 60-74 years old were more often intoxicated at the time of trauma (26\% vs $6 \%$ ) and other injuries $(25 \%$ vs $10 \%)$. They were also more likely to have contusions (35\% vs $10 \%)$ and less likely to have ASDH (34\% vs 76\%). They had fewer cases of hypertension/CVD (48\% vs 72\%) and antithrombotic drugs (30\% vs $62 \%$, warfarin $8 \%$ vs $42 \%$ ) and were more likely to have a history of ethylism $(30 \%$ vs $10 \%)$. These findings highlight important differences between the 60-74-year-old group, and the 75-89-year-old group. The differences were also reflected in patient management with the older group having more craniotomies than the younger group (60\% vs 38\%). This may be explained by the fact that ASDH was more common among patients 75-89 years old and consistently it was also found that the reason for craniectomy was $\mathrm{ASDH}$ in $56 \%$ in the older age group compared to $31 \%$ in the younger group (Table 2).

Looking for prognostic predictors in the medical history, none of the following, such as previous brain injury/disease, previous traumatic brain injury, diabetes mellitus, and ethylism, had any significant impact on favorable outcome in the univariate analysis or the multivariate analyses, which was unexpected (Tables 3, 4, and 5). This of course does not exclude that those factors do not influence clinical outcome, but simply means that we were unable to show significant differences with our data. The reasons for that may be that some of those factors were present in too large proportions of the patients and others in too small proportions, and that a
Fig. 3 Categorized outcome by age subdivided by 5 years. Outcome categorized in favorable (GOSE 5-8), unfavorable (GOSE 2-4), and dead (GOSE 1)

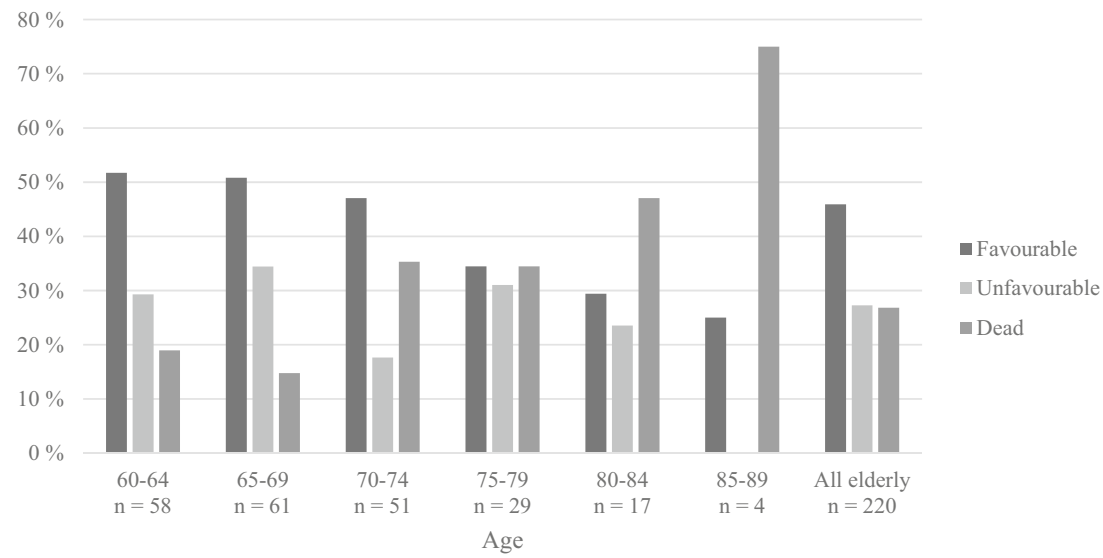


Table 3 Predictive value of admission and treatment variables for favorable outcome (univariate logistic regression analysis with favorable outcome (GOSE 5-8) as dependent variable)

\begin{tabular}{|c|c|c|c|c|c|}
\hline \multirow[t]{2}{*}{ Variables } & \multirow[t]{2}{*}{ Odds ratio } & \multicolumn{2}{|c|}{$95 \% \mathrm{CI}$} & \multirow[t]{2}{*}{$p$} & \\
\hline & & Lower & Upper & & \\
\hline Age & 0.948 & 0.908 & 0.989 & 0.013 & $*$ \\
\hline Sex (female) & 1.095 & 0.606 & 1.979 & 0.764 & \\
\hline GCS $\mathrm{M} \leq 3$ on admission & 0.161 & 0.046 & 0.562 & 0.004 & $* *$ \\
\hline Multiple injuries & 0.753 & 0.391 & 1.449 & 0.396 & \\
\hline Under the influence of drugs/alcohol at trauma & 0.728 & 0.378 & 1.403 & 0.343 & \\
\hline \multicolumn{6}{|l|}{ Marshall Classification } \\
\hline Diffuse injury I-IV & 3.189 & 1.828 & 5.565 & 0.000 & $* * *$ \\
\hline EML & 0.299 & 0.160 & 0.560 & 0.000 & $* * *$ \\
\hline NEML & 0.751 & 0.360 & 1.567 & 0.445 & \\
\hline \multicolumn{6}{|l|}{$\mathrm{CT}$ dominating injury type } \\
\hline Extracerebral hematoma & 0.619 & 0.361 & 1.059 & 0.080 & \\
\hline Contusions & 1.646 & 0.916 & 2.956 & 0.096 & \\
\hline All other & 1.082 & 0.591 & 1.981 & 0.797 & \\
\hline \multicolumn{6}{|l|}{ Medical history of } \\
\hline Brain injury/disease & 0.512 & 0.257 & 1.017 & 0.056 & \\
\hline Traumatic brain injury & 0.160 & 0.019 & 1.323 & 0.089 & \\
\hline Diabetes mellitus & 0.806 & 0.391 & 1.661 & 0.558 & \\
\hline Hypertension/CVD & 0.900 & 0.528 & 1.534 & 0.699 & \\
\hline Ethylism & 0.556 & 0.297 & 1.040 & 0.066 & \\
\hline Antithrombotic drugs & 1.028 & 0.594 & 1.779 & 0.921 & \\
\hline Antiplatelet & 1.899 & 0.993 & 3.632 & 0.053 & \\
\hline Warfarin & 0.435 & 0.197 & 0.960 & 0.039 & $*$ \\
\hline NOAC & 1.186 & 0.289 & 4.866 & 0.813 & \\
\hline LMWH & 1.184 & 0.234 & 5.998 & 0.839 & \\
\hline Surgery before arrival & 0.845 & 0.326 & 2.188 & 0.728 & \\
\hline Craniotomy & 0.412 & 0.237 & 0.716 & 0.002 & $* *$ \\
\hline Evacuated extracerebral hematoma & 0.498 & 0.286 & 0.868 & 0.014 & $*$ \\
\hline Evacuated contusions & 0.418 & 0.167 & 1.045 & 0.062 & \\
\hline Decompressive hemicraniectomy & 0.323 & 0.066 & 1.592 & 0.165 & \\
\hline Multiple surgeries & 1.200 & 0.497 & 2.897 & 0.685 & \\
\hline ICP monitoring & 0.634 & 0.371 & 1.082 & 0.095 & \\
\hline Mechanical ventilation & 0.253 & 0.122 & 0.526 & 0.000 & $* * *$ \\
\hline
\end{tabular}

larger patient material is required to show significant differences in outcome. It is obvious that established prognostic factors from large patient materials of all ages cannot be disregarded in the decision-making process for which elderly TBI patients should be treated.

Antithrombotic drugs as a group had no negative impact on outcome in the univariate analysis. However, in a subgroup analysis, warfarin was a significant prognostic factor and antiplatelet therapy showed marginal significance $(p=0.053)$, but neither showed any significant independent contribution in the multivariate analysis (Table 4, Table 5). This finding is in contrast to the results of many earlier studies and needs to be discussed in particular. Karni et al. found a $50 \%$ mortality rate for traumatic head injury in elderly with anticoagulants [18]. Lavoie et al. showed that preinjury warfarin in elderly with closed head injury had more severe head injury and a higher likelihood of death [20]. Franko et al. showed that warfarin carries a six-fold increase in TBI-mortality and that mortality and occurrence of intracerebral hemorrhage increased with higher international normalized ratio (INR), especially INR over 4.0 where the mortality was found to be $50 \%$ and the risk of intracerebral hematoma (ICH) $75 \%$ [12]. Grandhi et al. found that warfarin and not antiplatelet medication influenced survival and need for neurosurgical intervention in the elderly [14]. Pieracci et al. found that the degree of anticoagulation rather than warfarin itself predicts adverse 
Table 4 Prediction model of admission variables for favorable outcome (multivariate logistic regression analysis with favorable outcome (GOSE 5-8) as dependent variable)

\begin{tabular}{|c|c|c|c|c|c|c|c|c|}
\hline \multirow[t]{2}{*}{ Variables } & \multirow{2}{*}{$\begin{array}{l}\text { Regression } \\
\text { coefficient }\end{array}$} & \multirow[t]{2}{*}{ SE } & \multirow{2}{*}{$\begin{array}{l}\text { Wald } \\
X^{2}\end{array}$} & \multirow{2}{*}{$\begin{array}{l}\text { Odds } \\
\text { ratio }\end{array}$} & \multicolumn{2}{|c|}{$95 \% \mathrm{CI}$} & \multirow[t]{2}{*}{$p$} & \\
\hline & & & & & Lower & Upper & & \\
\hline Intercept & 4.114 & 2.032 & 4.101 & 61.192 & & & 0.043 & $*$ \\
\hline Age & -0.055 & 0.028 & 3.860 & 0.947 & 0.897 & 1.000 & 0.049 & $*$ \\
\hline Sex (female) & 0.056 & 0.366 & 0.023 & 1.057 & 0.516 & 2.167 & 0.879 & \\
\hline GCS $\mathrm{M} \leq 3$ on admission & -1.350 & 0.696 & 3.765 & 0.259 & 0.066 & 1.014 & 0.052 & \\
\hline Multiple injuries & -0.997 & 0.415 & 5.779 & 0.369 & 0.164 & 0.832 & 0.016 & $*$ \\
\hline $\begin{array}{l}\text { Under the influence of } \\
\text { drugs/alcohol at trauma }\end{array}$ & -0.135 & 0.492 & 0.076 & 0.874 & 0.333 & 2.290 & 0.783 & \\
\hline \multicolumn{9}{|l|}{ Marshall Classification } \\
\hline Diffuse injury I-IV & 0.521 & 0.478 & 1.189 & 1.684 & 0.660 & 4.300 & 0.275 & \\
\hline EML & -0.910 & 0.516 & 3.114 & 0.403 & 0.147 & 1.106 & 0.078 & \\
\hline \multicolumn{9}{|l|}{ CT dominating injury type } \\
\hline Extracerebral hematoma & 0.464 & 0.458 & 1.027 & 1.591 & 0.648 & 3.903 & 0.311 & \\
\hline Contusions & 0.296 & 0.416 & 0.508 & 1.345 & 0.595 & 3.036 & 0.476 & \\
\hline \multicolumn{9}{|l|}{ Medical history of } \\
\hline Brain injury/disease & -0.514 & 0.440 & 1.362 & 0.598 & 0.252 & 1.418 & 0.243 & \\
\hline Traumatic brain injury & -1.425 & 1.259 & 1.281 & 0.240 & 0.020 & 2.837 & 0.258 & \\
\hline Diabetes mellitus & -0.586 & 0.457 & 1.648 & 0.557 & 0.227 & 1.362 & 0.199 & \\
\hline Hypertension/CVD & 0.015 & 0.387 & 0.001 & 1.015 & 0.476 & 2.165 & 0.970 & \\
\hline Ethylism & -0.648 & 0.490 & 1.747 & 0.523 & 0.200 & 1.368 & 0.186 & \\
\hline \multicolumn{9}{|l|}{ Antithrombotic drugs } \\
\hline Antiplatelet & 0.540 & 0.434 & 1.548 & 0.523 & 0.200 & 1.368 & 0.213 & \\
\hline Warfarin & -0.764 & 0.517 & 2.184 & 1.717 & 0.733 & 4.021 & 0.139 & \\
\hline NOAC & -0.661 & 0.824 & 0.644 & 0.466 & 0.169 & 1.283 & 0.422 & \\
\hline LMWH & -0.597 & 1.024 & 0.340 & 0.516 & 0.103 & 2.594 & 0.560 & \\
\hline
\end{tabular}

outcome in TBI in elderly patients [35]. Ohm et al. showed that elderly with intracranial hemorrhage and antiplatelet therapy had increased mortality [32]. Wong et al. found in their study that clopidogrel increased mortality but not warfarin and aspirin [45]. There are also contradicting studies. In 2017, Ganetsky et al. examined 939 patients who had ground-level falls and antiplatelet therapy or anticoagulants, and found a low incidence of clinically significant intracranial hemorrhage $(<5 \%)$ and no difference between anticoagulation and antiplatelet therapy [13]. One could speculate that possible reasons for why anticoagulants did not have any prognostic significance in our study could be: (1) In our referral area, patients on warfarin have frequent check-ups which reduces the risk for overtreatment with too high INR. (2) National guidelines require CT examination after mild head trauma when on anticoagulation and prompt reversal of warfarin in case of intracranial hemorrhages. (3) Standardized NIC which minimizes secondary insults may prevent worsening of intracranial hemorrhages. Altogether, however, it is reasonable to assume that anticoagulation therapy increases the risk for worsening of the head injury and may under some circumstances complicate the insertion of ICP devices and surgical treatment, although such therapy doses not make successful management impossible.

Considering other possible prognostic factors analyzed in the univariate analysis, diffuse injury I-IV had a OR $>1$ and seems to be associated with favorable outcome (most likely due to the large number of diffuse injury II, the least serious class in that group). EML had an OR 0.299 indicating less chance of good outcome (Table 3). Both craniotomy and evacuated extracerebral hematoma had a negative influence on good outcome in the univariate analysis as well as mechanical ventilation (Table 3).

When analyzing potential prognostic factors, it is of utmost importance to identify factors with independent prognostic information. The multivariate analysis of prognostic admission factors for favorable outcome showed that high age and multiple injuries had a significant independent negative prognostic value and low GCS showed marginal significance $(p=$ 0.052) (Table 4), which was as expected and in accordance with other studies of elderly patients $[6,29,38,44]$. When both treatment factors and admission factors were included in the multivariate analysis of prognostic factors for favorable 
Table 5 Prediction model of admission and treatment variables for favorable outcome (multivariate logistic regression analysis with favorable outcome (GOSE 5-8) as dependent variable)

\begin{tabular}{|c|c|c|c|c|c|c|c|c|}
\hline \multirow[t]{2}{*}{ Variables } & \multirow{2}{*}{$\begin{array}{l}\text { Regression } \\
\text { coefficient }\end{array}$} & \multirow[t]{2}{*}{ SE } & \multirow{2}{*}{$\begin{array}{l}\text { Wald } \\
X^{2}\end{array}$} & \multirow{2}{*}{$\begin{array}{l}\text { Odds } \\
\text { ratio }\end{array}$} & \multicolumn{2}{|c|}{$95 \% \mathrm{CI}$} & \multirow[t]{2}{*}{$p$} & \\
\hline & & & & & Lower & Upper & & \\
\hline Intercept & 5.918 & 2.309 & 6.571 & 371.609 & & & 0.010 & $*$ \\
\hline Age & -0.064 & 0.031 & 4.240 & 0.938 & 0.882 & 0.997 & 0.039 & $*$ \\
\hline Sex (female) & 0.019 & 0.394 & 0.002 & 1.019 & 0.471 & 2.204 & 0.962 & \\
\hline GCS $\mathrm{M} \leq 3$ on admission & -1.727 & 0.768 & 5.061 & 0.178 & 0.039 & 0.801 & 0.024 & $*$ \\
\hline Multiple injuries & -1.077 & 0.466 & 5.342 & 0.340 & 0.137 & 0.849 & 0.021 & $*$ \\
\hline $\begin{array}{l}\text { Under the influence of } \\
\text { drugs/alcohol at trauma }\end{array}$ & -0.152 & 0.535 & 0.081 & 0.859 & 0.301 & 2.449 & 0.776 & \\
\hline \multicolumn{9}{|l|}{ Marshall Classification } \\
\hline Diffuse injury I-IV & 0.508 & 0.547 & 0.861 & 1.661 & 0.569 & 4.855 & 0.353 & \\
\hline EML & -1.157 & 0.631 & 3.359 & 0.314 & 0.091 & 1.084 & 0.067 & \\
\hline \multicolumn{9}{|l|}{ CT dominating injury type } \\
\hline Extracerebral hematoma & 0.070 & 0.541 & 0.017 & 1.073 & 0.371 & 3.098 & 0.897 & \\
\hline Contusions & 0.564 & 0.449 & 1.575 & 1.757 & 0.729 & 4.238 & 0.210 & \\
\hline \multicolumn{9}{|l|}{ Medical history of } \\
\hline Brain injury/disease & -0.685 & 0.486 & 1.987 & 0.504 & 0.194 & 1.307 & 0.159 & \\
\hline Traumatic brain injury & -1.398 & 1.313 & 1.133 & 0.247 & 0.019 & 3.241 & 0.287 & \\
\hline Diabetes mellitus & -0.684 & 0.499 & 1.878 & 0.505 & 0.190 & 1.342 & 0.171 & \\
\hline Hypertension/CVD & 0.158 & 0.419 & 0.141 & 1.171 & 0.515 & 2.664 & 0.707 & \\
\hline Ethylism & -0.961 & 0.536 & 3.217 & 0.383 & 0.134 & 1.093 & 0.073 & \\
\hline \multicolumn{9}{|l|}{ Antithrombotic drugs } \\
\hline Antiplatelet & 0.212 & 0.465 & 0.209 & 1.237 & 0.497 & 3.075 & 0.648 & \\
\hline Warfarin & -0.968 & 0.568 & 2.904 & 0.380 & 0.125 & 1.156 & 0.088 & \\
\hline NOAK & -0.349 & 0.859 & 0.165 & 0.706 & 0.131 & 3.797 & 0.685 & \\
\hline LMWH & -0.960 & 1.085 & 0.783 & 0.383 & 0.046 & 3.210 & 0.376 & \\
\hline Surgery before arrival & 1.480 & 0.765 & 3.746 & 4.395 & 0.981 & 19.681 & 0.053 & \\
\hline Craniotomy & -0.122 & 1.211 & 0.010 & 0.885 & 0.082 & 9.498 & 0.920 & \\
\hline $\begin{array}{l}\text { Evacuated extracerebral } \\
\text { hematoma }\end{array}$ & 1.020 & 1.099 & 0.862 & 2.773 & 0.322 & 23.898 & 0.353 & \\
\hline Evacuated contusions & -1.614 & 0.842 & 3.676 & 0.199 & 0.038 & 1.037 & 0.055 & \\
\hline $\begin{array}{l}\text { Decompressive } \\
\text { hemicraniectomy }\end{array}$ & -1.202 & 1.078 & 1.243 & 0.301 & 0.036 & 2.488 & 0.265 & \\
\hline Multiple surgeries & 0.473 & 0.614 & 0.595 & 1.605 & 0.482 & 5.344 & 0.441 & \\
\hline ICP monitoring & 0.489 & 0.433 & 1.276 & 1.630 & 0.698 & 3.806 & 0.259 & \\
\hline Mechanical ventilation & -1.637 & 0.548 & 8.910 & 0.195 & 0.066 & 0.570 & 0.003 & $* *$ \\
\hline
\end{tabular}

outcome, age, low GCS, and multiple injuries all had significant independent negative prognostic value. Surgery before arrival (evacuated ASDH at the referring hospital) showed positive prognostic value of marginal significance $(p=$ 0.053). Evacuation of contusions and extracerebral hemato$\mathrm{ma}$, which were significant prognostic factors in the univariate analysis, did not show any significant independent influence on clinical outcome, although evacuation of contusions had marginal significant $(p=0.055)$. Mechanical ventilation on the other hand proved to have independent negative predictive value for favorable outcome (OR 0.195) (Table 5). The reasonable explanation for that may be that mechanical ventilation is not completely dependent on the severity of brain injury but also related to other factors not included in the statistical analysis, e.g., various infections including lung infections and other adverse events. Barnato et al. also found that elderly treated at the intensive care unit who survived mechanical ventilation had worse functional outcome [2]. It is likely that the negative impact of mechanical ventilation on outcome depends both on a more severe brain injury requiring mechanical ventilation, and on the development of systemic complications, with which the elderly are less able to cope.

There are some study limitations that needs to be considered. This is a single-center study and the results may have been influenced by the local management applied, and therefore the results may not be completely generalizable. Furthermore, as mentioned earlier, there was a selection bias since predominantly patients judged to have a reasonable chance for favorable outcome were accepted for NIC. Therefore, the results need to be interpreted with caution.

While these results may at first look discouraging but for this group of elderly TBI patients, a relatively large proportion achieved favorable outcome, when they were treated according to modern NIC principles and the treatment did not cause a large proportion of patients with severe disability or vegetative state. Similar results have also been reported by others [24, 29, 
37, 47]. Further studies are required focusing on the NIC specifically in elderly TBI patients concerning, e.g., secondary insults, ICP management, and cerebral perfusion thresholds, to find out if these areas holds the key to improve outcome.

\section{Conclusion}

This study shows that an appropriately selected group of elderly TBI patients receiving modern NIC have a fair chance of favorable outcome without large risks for severe deficits and vegetative state. Significant negative prognostic factors were high age, multiple injuries, low GCS M on admission, and the use of mechanical ventilation. The results underline that elderly with TBI should have access to NIC, when favorable outcome is as high as $47 \%$ for patients $60-74$ years and around $30 \%$ for the patients between 75 and 84 years. Further research is needed about the selection of elderly patients and the optimal NIC management of elderly with TBI.

Funding The study was supported by grants from the Uppsala university hospital.

\section{Compliance with ethical standards}

Conflict of interest The authors declare that they have no conflict of interest.

Research involving human participants and animals All procedures performed in studies involving human participants were in accordance with the ethical standards of the institutional and/or national research committee and with the 1964 Helsinki declaration and its later amendments or comparable ethical standards. This article does not contain any studies with animals performed by any of the authors.

The study was approved by the Local ethical review board.

Informed consent Informed consent was obtained from individual participants or the relatives if the participant did not have the decisionmaking capacity for informed consent.

Open Access This article is distributed under the terms of the Creative Commons Attribution 4.0 International License (http:// creativecommons.org/licenses/by/4.0/), which permits unrestricted use, distribution, and reproduction in any medium, provided you give appropriate credit to the original author(s) and the source, provide a link to the Creative Commons license, and indicate if changes were made.

\section{References}

1. Andrews BT, Pitts LH (1991) Functional recovery after traumatic transtentorial herniation. Neurosurgery 29:227-231

2. Barnato AE, Albert SM, Angus DC, Lave JR, Degenholtz HB (2011) Disability among elderly survivors of mechanical ventilation. Am J Respir Crit Care Med 183:1037-1042. https://doi.org/ 10.1164/rccm.201002-0301OC

3. Becker DP, Miller JD, Ward JD, Greenberg RP, Young HF, Sakalas $\mathrm{R}$ (1977) The outcome from severe head injury with early diagnosis and intensive management. J Neurosurg 47:491-502. https:/doi. org/10.3171/jns.1977.47.4.0491

4. Bowers SA, Marshall LF (1980) Outcome in 200 consecutive cases of severe head injury treated in San Diego County: a prospective analysis. Neurosurgery 6:237-242

5. Cheng C, Chi NC, Williams E, Thompson HJ (2018) Examining age-related differences in functional domain impairment following traumatic brain injury. Int J Older People Nursing:e12208. https:// doi.org/10.1111/opn.12208

6. Chestnut RM, Ghajar J, Maas AIR, Marion DW, Servadei F, Teasdale G, Unterberg A, von Holst H, Walter BC (2000) Part 2: early indicators of prognosis in severe traumatic BRAIN injury. J Neurotrauma 17:555-555. https://doi.org/10.1089/neu.2000.17. 555

7. Combes P, Fauvage B, Colonna M, Passagia JG, Chirossel JP, Jacquot C (1996) Severe head injuries: an outcome prediction and survival analysis. Intensive Care Med 22:1391-1395

8. Dams-O'Connor K, Cuthbert JP, Whyte J, Corrigan JD, Faul M, Harrison-Felix C (2013) Traumatic brain injury among older adults at level I and II trauma centers. J Neurotrauma 30:2001-2013. https://doi.org/10.1089/neu.2013.3047

9. Eker C, Asgeirsson B, Grande PO, Schalen W, Nordstrom CH (1998) Improved outcome after severe head injury with a new therapy based on principles for brain volume regulation and preserved microcirculation. Crit Care Med 26:1881-1886

10. Elf K, Nilsson P, Enblad P (2002) Outcome after traumatic brain injury improved by an organized secondary insult program and standardized neurointensive care. Crit Care Med 30:2129-2134. https://doi.org/10.1097/01.CCM.0000025893.73582.52

11. Fischerström A, Nyholm L, Lewén A, Enblad P (2014) Acute neurosurgery for traumatic brain injury by general surgeons in Swedish county hospitals: a regional study. Acta Neurochir 156:177-185. https://doi.org/10.1007/s00701-013-1932-5

12. Franko J, Kish KJ, O'Connell BG, Subramanian S, Yuschak JV (2006) Advanced age and preinjury warfarin anticoagulation increase the risk of mortality after head trauma. J Trauma 61:107110. https://doi.org/10.1097/01.ta.0000224220.89528.fc

13. Ganetsky M, Lopez G, Coreanu T, Novack V, Horng S, Shapiro NI, Bauer KA (2017) Risk of intracranial hemorrhage in ground-level fall with antiplatelet or anticoagulant agents. Acad Emerg Med 24: 1258-1266. https://doi.org/10.1111/acem.13217

14. Grandhi R, Harrison G, Voronovich Z, Bauer J, Chen SH, Nicholas D, Alarcon LH, Okonkwo DO (2015) Preinjury warfarin, but not antiplatelet medications, increases mortality in elderly traumatic brain injury patients. J Trauma Acute Care Surg 78:614-621. https://doi.org/10.1097/TA.0000000000000542

15. Hawley C, Sakr M, Scapinello S, Salvo J, Wrenn P (2017) Traumatic brain injuries in older adults- 6 years of data for one UK trauma Centre: retrospective analysis of prospectively collected data. Emerg Med J 34:509-516. https://doi.org/10.1136/emermed2016-206506

16. Hukkelhoven CW, Steyerberg EW, Rampen AJ, Farace E, Habbema JD, Marshall LF, Murray GD, Maas AI (2003) Patient age and outcome following severe traumatic brain injury: an analysis of 5600 patients. J Neurosurg 99:666-673. https://doi.org/10. 3171/jns.2003.99.4.0666

17. Iaccarino C, Carretta A, Nicolosi F, Morselli C (2018) Epidemiology of severe traumatic brain injury. J Neurosurg Sci 62:535-541. https://doi.org/10.23736/S0390-5616.18.04532-0

18. Karni A, Holtzman R, Bass T, Zorman G, Carter L, Rodriguez L, Bennett-Shipman VJ, Lottenberg L (2001) Traumatic head injury in the anticoagulated elderly patient: a lethal combination. Am Surg 67:1098-1100

19. Koskinen S, Alaranta H (2008) Traumatic brain injury in Finland 1991-2005: a nationwide register study of hospitalized and fatal 
TBI. Brain Inj 22:205-214. https://doi.org/10.1080/ 02699050801938975

20. Lavoie A, Ratte S, Clas D, Demers J, Moore L, Martin M, Bergeron E (2004) Preinjury warfarin use among elderly patients with closed head injuries in a trauma center. J Trauma 56:802-807

21. LeBlanc J, de Guise E, Gosselin N, Feyz M (2006) Comparison of functional outcome following acute care in young, middle-aged and elderly patients with traumatic brain injury. Brain Inj 20:779-790. https://doi.org/10.1080/02699050600831835

22. Lenell S, Nyholm L, Lewen A, Enblad P (2015) Updated periodic evaluation of standardized neurointensive care shows that it is possible to maintain a high level of favorable outcome even with increasing mean age. Acta Neurochir 157:417-425. https://doi.org/ 10.1007/s00701-014-2329-9

23. Lennartsson C, Heimerson I (2012) Elderly people's health: health in Sweden: the National Public Health Report 2012. Chapter 5. Scand J Public Health 40:95-120. https://doi.org/10.1177/ 1403494812459468

24. Li LF, Lui WM, Wong HH, Yuen WK, Leung GK (2017) Outcome after operative intervention for traumatic brain injuries in the elderly. Asian J Neurosurg 12:37-43. https://doi.org/10.4103/17935482.148787

25. Marshall LF, Marshall SB, Klauber MR, Clark MB, Eisenberg HM, Jane JA, Luerssen TG, Marmarou A, Foulkes MA (1991) A new classification of head injury based on computerized tomography. Spec Suppl 75:S14-S20. https://doi.org/10.3171/sup.1991.75.1s.0s14

26. Marshall LF, Smith RW, Shapiro HM (1979) The outcome with aggressive treatment in severe head injuries. Part I: the significance of intracranial pressure monitoring. J Neurosurg 50:20-25. https:// doi.org/10.3171/jns.1979.50.1.0020

27. Marshall LF, Smith RW, Shapiro HM (1979) The outcome with aggressive treatment in severe head injuries. Part II: acute and chronic barbiturate administration in the management of head injury. $\mathrm{J}$ Neurosurg 50:26-30. https://doi.org/10.3171/jns.1979.50.1.0026

28. Merzo A, Lenell S, Nyholm L, Enblad P, Lewen A (2016) Promising clinical outcome of elderly with TBI after modern neurointensive care. Acta Neurochir 158:125-133. https://doi.org/ 10.1007/s00701-015-2639-6

29. Mosenthal AC, Lavery RF, Addis M, Kaul S, Ross S, Marburger R, Deitch EA, Livingston DH (2002) Isolated traumatic brain injury: age is an independent predictor of mortality and early outcome. $\mathrm{J}$ Trauma 52:907-911

30. Nordstrom CH, Sundbarg G, Messeter K, Schalen W (1989) Severe traumatic brain lesions in Sweden. Part 2: impact of aggressive neurosurgical intensive care. Brain Inj 3:267-281

31. Nyholm L, Howells T, Enblad P, Lewén A (2013) Introduction of the Uppsala Traumatic Brain Injury register for regular surveillance of patient characteristics and neurointensive care management including secondary insult quantification and clinical outcome. Ups J Med Sci 118:169-180. https://doi.org/10.3109/03009734.2013.806616

32. Ohm C, Mina A, Howells G, Bair H, Bendick P (2005) Effects of antiplatelet agents on outcomes for elderly patients with traumatic intracranial hemorrhage. J Trauma 58:518-522

33. Pedersen K, Fahlstedt M, Jacobsson A, Kleiven S, von Holst H (2015) A national survey of traumatic brain injuries admitted to hospitals in Sweden from 1987 to 2010. Neuroepidemiology 45: 20-27. https://doi.org/10.1159/000381780

34. Peeters W, Majdan M, Brazinova A, Nieboer D, Maas AIR (2017) Changing epidemiological patterns in traumatic brain injury: a longitudinal hospital-based study in Belgium. Neuroepidemiology 48: 63-70. https://doi.org/10.1159/000471877

35. Pieracci FM, Eachempati SR, Shou J, Hydo LJ, Barie PS (2007) Degree of anticoagulation, but not warfarin use itself, predicts adverse outcomes after traumatic brain injury in elderly trauma patients. J Trauma 63:525-530. https://doi.org/10.1097/TA. 0b013e31812e5216

36. Sjörgen H, Björnstig U (1991) Injuries among the elderly in the home environment:detailed analysis of mechanisms and consequences. J Aging Health 3:107-125. https://doi.org/10.1177/ 089826439100300106

37. Stocchetti N, Paternò R, Citerio G, Beretta L, Colombo A (2012) Traumatic brain injury in an aging population. J Neurotrauma 29: 1119-1125. https://doi.org/10.1089/neu.2011.1995

38. Susman M, DiRusso SM, Sullivan T, Risucci D, Nealon P, Cuff S, Haider A, Benzil D (2002) Traumatic brain injury in the elderly: increased mortality and worse functional outcome at discharge despite lower injury severity. J Trauma 53:219-223 discussion 223214

39. Teasdale GM, Pettigrew LE, Wilson JT, Murray G, Jennett B (1998) Analyzing outcome of treatment of severe head injury: a review and update on advancing the use of the Glasgow Outcome Scale. J Neurotrauma 15:587-597

40. Thomas KE, Stevens JA, Sarmiento K, Wald MM (2008) Fallrelated traumatic brain injury deaths and hospitalizations among older adults-United States, 2005. J Saf Res 39:269-272. https:// doi.org/10.1016/j.jsr.2008.05.001

41. Unterhofer C, Ho WM, Wittlinger K, Thome C, Ortler M (2017) "I am not afraid of death"-a survey on preferences concerning neurosurgical interventions among patients over 75 years. Acta Neurochir 159:1547-1552. https://doi.org/10.1007/s00701-0173240-y

42. Wettervik TS, Lenell S, Nyholm L, Howells T, Lewen A, Enblad P (2018) Decompressive craniectomy in traumatic brain injury: usage and clinical outcome in a single centre. Acta Neurochir 160:229 237. https://doi.org/10.1007/s00701-017-3418-3

43. Wilson JT, Pettigrew LE, Teasdale GM (1998) Structured interviews for the Glasgow Outcome Scale and the extended Glasgow Outcome Scale: guidelines for their use. J Neurotrauma 15:573585

44. Vollmer DG, Torner JC, Jane JA, Sadovnic B, Charlebois D, Eisenberg HM, Foulkes MA, Marmarou A, Marshall LF (1991) Age and outcome following traumatic coma: why do older patients fare worse? Spec Suppl 75:S37-S49. https://doi.org/10.3171/sup. 1991.75.1s.0s37

45. Wong DK, Lurie F, Wong LL (2008) The effects of clopidogrel on elderly traumatic brain injured patients. J Trauma 65:1303-1308. https://doi.org/10.1097/TA.0b013e318185e234

46. World Population Prospects (2017) The 2017 Revision, Volume II: Demographic Profiles. ST/ESA/SER.A/400. United Nations, Department of Economic and Social Affairs, Population Division

47. Wutzler S, Lefering R, Wafaisade A, Maegele M, Lustenberger T, Walcher F, Marzi I, Laurer H, TraumaRegister DGU (2015) Aggressive operative treatment of isolated blunt traumatic brain injury in the elderly is associated with favourable outcome. Injury 46:1706-1711. https://doi.org/10.1016/j.injury.2015.02.013

48. Wärme PE, Bergström R, Persson L (1991) Neurosurgical intensive care improves outcome after severe head injury. Acta Neurochir 110:57-64

Publisher's note Springer Nature remains neutral with regard to jurisdictional claims in published maps and institutional affiliations. 